\title{
Determinants of disease acceptance in renal transplantation patients assessed with the application of Acceptance IIIness Scale (AIS)
}

\author{
Olga Fedorowicz ${ }^{1,2}$, Ewa Jaźwińska-Tarnawska ${ }^{1}$, Arkadiusz Adamiszak ${ }^{1}$, Przemysław Niewiński ${ }^{1}$, Magdalena \\ Krajewska $^{3}$, Anna Wiela-Hojeńska ${ }^{1}$ \\ ${ }^{1}$ Department of Clinical Pharmacology, Wroclaw Medical University, Wroclaw, Poland; ${ }^{2}$ Clinical Pharmacy Team, Jan \\ Mikulicz-Radecki University Teaching Hospital, Wroclaw, Poland; ${ }^{3}$ Department of Nephrology and Transplantation \\ Medicine, Wroclaw Medical University, Wroclaw, Poland
}

Corresponding author: Olga Fedorowicz, Department of Clinical Pharmacology, Wroclaw Medical University; 211a Borowska St., 50-556 Wroclaw, Poland; email: olga.fedorowicz@umed.wroc.pl

Received, December 28, 2020; Revised, May 11, 2021; Accepted, June 10, 2021; Published, June 15, 2021

\begin{abstract}
Purpose: Kidney transplant patients require long-term pharmacotherapy with a significant risk of drug-related complications. The disease acceptance may significantly affect the effectiveness, safety, and patient adherence to their treatment. The purpose of this study was to evaluate, for kidney transplantation patients, the essential determinants for better disease acceptance, and whether a clinical pharmacist may influence its degree. Methods: The study involved 201 renal graft patients aged 18-81 years. The diagnostic survey method with the questionnaire of the Acceptance Illness Scale (AIS) and authors' query was used to obtain sociodemographic and co-morbidities data, the number of medications taken, the therapy cost, a patient needs for more attention from medical staff, and their willingness to cooperate with a clinical pharmacist. Results: The largest group (55.2\%) of patients demonstrated a high level of acceptance of their health. However, in every disease acceptance score range (low, medium, high), the score was statistically lower in patients over 50 years of age $\left(\chi^{2}=7.27, \mathrm{p}=0.026\right)$, occupationally inactive $\left(\chi^{2}=13.8, \mathrm{p}<0.001\right)$, over 5 medicines taken $\left(\chi^{2}=7.77, \mathrm{p}=0.020\right)$, and declaring too much expenditure on the therapy $\left(\chi^{2}=14.3, \mathrm{p}<0.001\right)$. The assessment established a statistically significant negative correlation between the number of chronic conditions and the AIS score $(\mathrm{R}=-0.32, \mathrm{p}<0.001)$. The lower number of coexisting chronic diseases the better disease acceptance. Moreover, patients reporting the need for more attention from the health service and willing to consult a pharmacist cope in a statistically significant way worse with accepting their health $\left(\chi^{2}=15.1\right.$ and $\mathrm{p}<0.001, \chi^{2}=6.76$ and $\mathrm{p}=0.034$ respectively). Conclusion: For post-transplantation patients, factors affecting the acceptance of illness should be taken into consideration while planning medical care. The reported need for professional assistance indicates necessity for establishing a multidisciplinary therapeutic team in which a clinical pharmacist should play a special role.
\end{abstract}

\section{INTRODUCTION}

Kidney transplantation is considered the most effective method of therapy of chronic kidney disease, prolonging life, and improving its quality. However, it intensifies a risk of surgical complications, infections, wound healing disorders, urine leakage or stenosis of the urinary tract and the need to perform surgery $(1,2,3)$. Moreover, chronic immunosuppression increases the hazard of developing infections and cancer and a decrease in glomerular filtration rate is a risk factor for cardiovascular events. Glucocorticosteroids and calcineurin inhibitors can cause NODAT (new-onset diabetes after transplantation). Additionally, calcineurin inhibitors have a nephrotoxic potential. Hyperlipidemia, myelosuppression, or renal impairment are undesirable effects of mammalian target of rapamycin (mTOR) protein inhibitors
$(4,5)$. Anemia $(45-70 \%)$ may be provoked by impaired renal function, thrombotic microangiopathy or immunosuppressants. Patients also experience sleep problems, anxiety and depressive disorders, weight gain, and hair loss $(1,4,6)$. The risk factors for the occurrence of hypertension include age, presence of renal artery stenosis, period of ischemia of the transplanted organ, renal artery and vein anastomosis, rejection, type A receptor angiotensin AT1R antibodies related to rejection. Appearance of diabetes depends on transplant type, immunosuppression (glucocorticosteroids, tacrolimus, cyclosporine, sirolimus combined with calcineurin inhibitors) and presence of electrolyte disturbances, cytomegalovirus infection or past rejection episodes. Urinary tract infections are enhanced by prolonged bladder catheterization, stenting of the urinary tract with the urethral catheter, vesicoureteral reflux, vesicoureteral 
anastomosis/stenosis, concentrated transplant perfusion solution, cytomegalovirus infection, acute rejection episodes, reduced transplant function, four-drug immunosuppression protocols with anti-thymocyte globulin or basiliximab induction, three-drug protocols containing azathioprine and/or mycophenolate sodium/mofetil $(4,6)$.

Kidney transplantation patients experience deterioration of the psychophysical condition and social functioning. Acceptance of the disease means to resign oneself to a certain loss, limitations and changes in the current life and requires adapting to a new situation. The higher the degree of acceptance, the better adherence to the therapy regime, less negative emotions, and higher motivation of the patient for their cognitive and causative activity, which all affect life satisfaction $(7,8)$. The assessment of disease acceptance enables the recognition of needs, thus optimizing the treatment, prevention of complications and comprehensive care, enhancing education and patient's good cooperation and allowing for holistic nephrological and emotional support tailored to their needs.

The problem of the disease acceptance among kidney post-transplantation patients and, so far, determinants influencing its level was not examined in the literature in detail. Previous studies concern heterogeneous groups of patients with renal failure and refer not to the degree of disease acceptance according to a standardized rating scale but to the assessment of their quality of life (9), or the acceptance of increased risk of viral infection such as HIV from kidney donors (10).

In this study, several factors were identified that may affect the acceptance of the illness; these should be taken into account during posttransplantation care. Application of Acceptance Illness Scale (AIS) with additional sociodemographic questions could be used to identify patients who would demand more attention and extended care in order to achieve and improve the therapeutical goals.

The study aimed to evaluate, for kidney transplantation patients, the determinants for disease acceptance, and whether a clinical pharmacist may influence its degree.

\section{METHODS}

\section{Study Design}

The study used the diagnostic survey method with the questionnaire of the Acceptance Illness Scale (AIS) by Felton, Revenson and Hinrichsen, adapted to Polish conditions by Juczyński (the reliability measured by the Cronbach coefficient was 0.85 ). The Scale consists of 8 statements concerning the consequences of poor health in terms of: assessment of limitations caused by the disease, lack of self-sufficiency, sense of dependence on others and decreased self-esteem. The examined patient determined his/her current condition on the five-level Likert scale where: 1 means - Strongly agree, 2 - Agree, 3 - I don't know, 4 - Disagree, 5 - Strongly disagree. The measure of the degree of acceptance of the disease was the score from 8 to 40 . The lower the score, the worse the acceptance and adaptation to the disease, the lower self-esteem and higher severity of negative emotions accompanying the disease and treatment, and the stronger sense of mental discomfort $(11,12)$. The score indicates the level of the disease acceptance: between 8 and 19 - low or no acceptance; 20-35 - medium; and 36-40 - high $(12,13)$.

Furthermore, the original author's questionnaire was applied to obtain sociodemographic and co-morbidities data, the number of medications taken, the cost of therapy and the patient's functioning after transplantation.

Renal transplantation patients were hospitalized at the Department of Nephrology and Transplantation Medicine of University Teaching Hospital in Wroclaw, Poland. The inclusion criteria for the study were: kidney transplantation history, age over 18 , and consent to voluntary, informed participation in the project. Patients with other conditions leading to renal failure, but without organ transplantation, were not included in the study.

Prior to the survey, each patient was informed about its course and purpose and the way of collecting and processing the personal data.

The project was approved by Bioethical Committee operating at Wroclaw Medical University (No KB - 57/2019).

\section{Statistical Analysis}

The analysis was carried out using the Statistica version 13.3 (TIBCO Software Inc., Palo Alto, CA, USA). The assessed continuous parameters were represented by the median and the interquartile range. The verification of the hypothesis was performed with the Mann-Whitney U nonparametric test (the heterogeneity of variance was tested by Bartlett's test). Verification of the obtained data significance was carried out further using Bonferroni method of error analysis. Effect of parameters such as age, vocational activity etc. on AIS was evaluated via multivariate analysis using backward stepwise linear regression. For discrete parameters, the frequency of the feature in 
groups was analysed by the chi-square test. The Spearman's correlation coefficient was calculated for a chosen group of parameters pairs. $P$ values below 0.05 were considered as statistically significant.

\section{RESULTS}

\section{Patient Characteristics}

A total of 201 renal transplantation patients $(88$ women, 113 men) were involved in the study. The median patient age was 57 years (range 43-65 and interquartile range 18-81years), 88 women aged 55 years (range 43-64.5 and interquartile range 18-81 years), and 113 men aged 58 years (range 43-65 and interquartile range $24-78$ years). In the study population, male patients (113) dominate slightly $(56 \%), 133$ lived in the city $(66 \%), 131$ were married (65\%), 78 had secondary (39\%) and 64 vocational $(32 \%)$ education, 68 persons $(32 \%)$ were working, $72(36 \%)$ were retired pensioners and majority 167 suffered from co-morbidities $(83 \%)$ (Table 1). The average time after the kidney transplantation was \pm 7.5 years.

\section{The Acceptance Illness Scale (AIS)}

Table 2 presents the summary of the percentage distribution of responses given by renal transplantation patients to the statements contained in the Acceptance Illness Scale.

Of all analysed areas, the highest percentage of positive responses (Strongly agree + Agree) was attributed to the statements "due to my health condition I am not able to do what I like most" and "I will never be self-sufficient as much as I would like to," which are the least accepted life situations. The lowest percentage of positive answers was given to the statement "illness makes me a burden for my family and friends." Therefore, it can be assumed that the patients receive adequate support from their nearest ones.

As the first result, it was shown that the majority (111) of patients (55.2\%) presented a high level of disease acceptance, 77 - medium (38.3\%) and 13 - low level $(6.47 \%)$.

The next goal was to determine a relationship between the disease acceptance level and one of the variables (features) from the authors' questionnaire. To this end, patients in each of AIS score ranges were divided into two groups: conforming or not with the given feature (e.g., for the variable "marital status", one group was formed by married persons and another by singles) (Table $3)$.

Statistically significant correlations between the disease acceptance level and gender, marital status, place of residence, level of education or time elapsed since transplantation was not confirmed. Then the correlation between the occurrence of this feature and the AIS score was calculated.

Essential determinants for better disease acceptance were: age below 50 (chi-square test $=7.27, \mathrm{p}=0.026$ ); vocational activity (chi-square test $=13.8, \mathrm{p}=0.001$ ); number of taken medicines less than 5 (chi-square test $=7.77, \mathrm{p}=0.021$ ); no additional diseases (chi-square test $=10.3$, $\mathrm{p}=0.006$ ); and acceptance of treatment costs (chisquare test $=14.3, \mathrm{p}=0.001$ ). Patients with these features did not see the necessity either for pharmacist assistance or additional attention from medical staff.

The assessment established a statistically significant negative correlation (Spearman's correlation) between the number of chronic conditions and the AIS score $(\mathrm{R}=-0.32, \mathrm{p}=0.001)$. The lower number of coexisting chronic diseases the better disease acceptance (Figure 1).

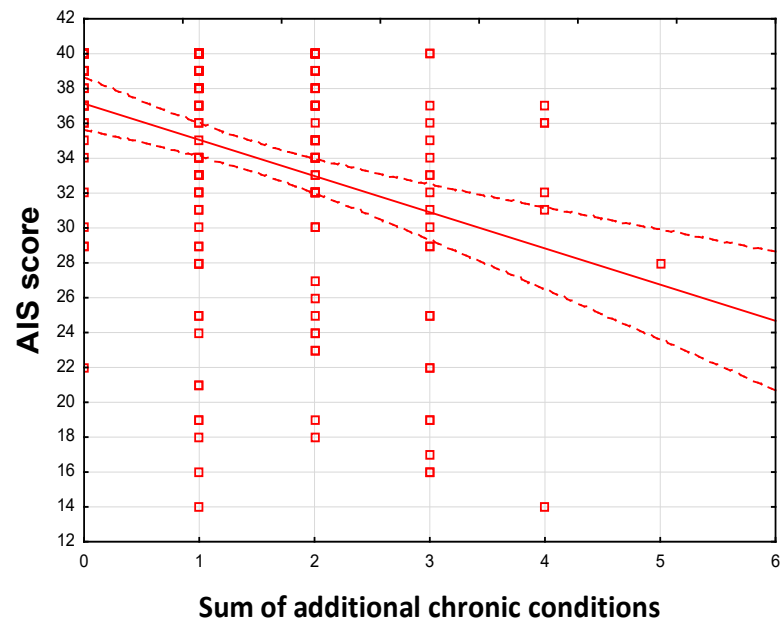

Figure 1. The relation between the disease acceptance level and the number of additional chronic conditions in renal post transplantation patients.

After performing multivariate analysis using backward stepwise linear regression of AIS $=\mathrm{f}$ (age, vocational activity, number of taken medicines, additional diseases, acceptance of treatment costs, pharmacist's assistance, attention from medical staff), it was found that vocational activity, additional diseases, acceptance of treatment costs, pharmacist's assistance have an independent effect on $\operatorname{AIS}\left(\mathrm{n}=201, \mathrm{R}=0.45, \mathrm{R}^{2}=0.21\right.$, adjusted $\mathrm{R}=0.19$, $\mathrm{p}=0.000)$.

One of the most studied aspects was also the opinion of a patient on the need for more attention from medical staff and the usefulness of pharmacist's help. In both aspects, it was demonstrated in a statistically significant way (chisquare test $=15.1$ and $\mathrm{p}=0.001$, chi-square test $=6.76$ 
Table 1. Sociodemographic data of renal transplantation patients involved in the study.

\begin{tabular}{|c|c|c|c|}
\hline Factor & Category & $\begin{array}{c}\text { Number } \\
\text { of patients } \\
\mathbf{N}=\mathbf{2 0 1}\end{array}$ & $\begin{array}{l}\text { Percentage of } \\
\text { patients }(\%)\end{array}$ \\
\hline \multirow{2}{*}{ Gender } & female & 88 & 44 \\
\hline & male & 113 & 56 \\
\hline \multirow{2}{*}{ Place of residence } & country & 68 & 34 \\
\hline & city & 133 & 66 \\
\hline \multirow{5}{*}{ Marital status } & married & 131 & 65 \\
\hline & single & 38 & 19 \\
\hline & widowed & 16 & 8 \\
\hline & divorced & 16 & 8 \\
\hline & separated & 0 & 0 \\
\hline \multirow{4}{*}{ Education } & primary & 16 & 8 \\
\hline & vocational & 64 & 32 \\
\hline & secondary & 78 & 39 \\
\hline & higher & 43 & 21 \\
\hline \multirow{5}{*}{$\begin{array}{l}\text { Vocational } \\
\text { situation }\end{array}$} & pupil/student & 2 & 1 \\
\hline & vocationally active & 68 & 32 \\
\hline & unemployed & 4 & 2 \\
\hline & retirement pensioner & 72 & 36 \\
\hline & disabled pensioner & 55 & 27 \\
\hline \multirow{4}{*}{$\begin{array}{l}\text { Comorbidity in kidney } \\
\text { recipients }\end{array}$} & hypertension & 145 & 72 \\
\hline & other cardiovascular diseases & 47 & 23 \\
\hline & diabetes & 34 & 17 \\
\hline & other diseases & 12 & 6 \\
\hline
\end{tabular}

and $\mathrm{p}=0.034$ respectively) that patients reporting the need for more attention from the health services and their willingness to consult a pharmacist cope worse with accepting their health. It can be concluded that with the decreasing acceptance of one's health, the patient's interest in cooperating with a pharmacist in the ward and/or the clinic increases.

\section{DISCUSSION}

Transplantation is a particularly stressful event, requiring the patient to activate bio-psycho-social skills in order to accept and integrate the new organ both physically and mentally. Therefore, a prior assessment of the psychological profile and personality of the transplant recipient is very important to reduce the role of factors that affect the outcome of surgery and the patient's emotional state $(1,6,14)$. In the majority of cases kidney transplantation provides a significant improvement in the quality of life and health. However, patients are struggling with a chronic disease and related problems, the occurrence of adverse effects of immunosuppressants or the risk of acute organ rejection (15). Their lifestyle, social roles and concepts of the world and identity are revised. The patient's attitude towards the disease also influences the active involvement in the therapy process by adherence to the appropriate frequency and time of taking medications, controlling their undesirable effects, and noting interactions (16).

Therefore, it was justified to undertake the research to assess the degree of acceptance and identify the factors determining this parameter in renal transplant recipients, since the available literature has little data on this subject, and the obtained results may significantly optimize patient care.

The standardized Scale for Disease Acceptance was used as the research tool. It should be mentioned that comparing observations of different authors using AIS is difficult due to different ranges in the three-point scales indicating 
a low, medium and especially- high degree of disease acceptance. The values of 8-19, 20-35 and $36-40$ respectively and the values of 20 and 36 as the separating value, were used in our study $(12,13)$. The most popular is the interpretation in which scores below 20 points are considered a poor result, and above 30 a very good level of acceptance of one's condition (11). Due to the few reports concerning the acceptance in kidney transplantation patients, our results were compared with the observations regarding patients with other chronic diseases.

The average AIS score in our study was relatively high (34.1) which means a high degree of disease acceptance. Similar values were obtained in patients 30 days and 6 months after the implantation of a cardiac electrotherapy device
(31.4; 34.6), in patients with critical lower limb ischemia after the surgery (score 32) $(12,17)$.

Lower values on the AIS scale, and therefore the worse acceptance of the disease, were found in women with osteoporosis (22.2), patients on peritoneal dialysis (23.2), dialyzed patients (24), systemic connective tissue diseases (24.5), multiple sclerosis (24.2), epilepsy (25.1) and ulcerative colitis (29.7) (11,12,18-22). Greater disability, also in mobility, is associated with a higher level of depression and poorer acceptance of the disease. Depression reduces motivation and adversely affects the effectiveness of rehabilitation of patients after stroke or with multiple sclerosis $(20,23)$. In our study, the estimated disease acceptance rate was significantly affected by several factors, age, vocationally activity

Table 2. Analysis of disease acceptance according to the AIS scale score in renal transplantation patients

Percentage of answers $(\%)$

\begin{tabular}{|c|c|c|c|c|c|c|}
\hline Statement & $\begin{array}{l}\text { Strongly } \\
\text { agree }\end{array}$ & Agree & I don't know & Disagree & $\begin{array}{l}\text { Strongly } \\
\text { disagree }\end{array}$ & $\begin{array}{l}\text { Summary of } \\
\text { answers }\end{array}$ \\
\hline \multirow{2}{*}{$\begin{array}{l}\text { I am having trouble } \\
\text { adapting to the restrictions } \\
\text { imposed by the disease }\end{array}$} & 6.47 & 8.96 & 5.47 & 11.4 & 67.7 & 100 \\
\hline & $\mathrm{n}=13$ & $\mathrm{n}=18$ & $\mathrm{n}=11$ & $\mathrm{n}=23$ & $\mathrm{n}=136$ & $\mathrm{n}=201$ \\
\hline \multirow{2}{*}{$\begin{array}{l}\text { Because of my health, I } \\
\text { can't do what I like best }\end{array}$} & 8.96 & 15.4 & 8.46 & 11.4 & 55.7 & 100 \\
\hline & $\mathrm{n}=18$ & $\mathrm{n}=31$ & $\mathrm{n}=17$ & $\mathrm{n}=23$ & $\mathrm{n}=112$ & $\mathrm{n}=201$ \\
\hline \multirow{2}{*}{$\begin{array}{l}\text { The disease sometimes } \\
\text { makes me feel unnecessary }\end{array}$} & 4.98 & 4.48 & 2.99 & 12.4 & 75.1 & 100 \\
\hline & $\mathrm{n}=10$ & $\mathrm{n}=9$ & $\mathrm{n}=6$ & $\mathrm{n}=25$ & $\mathrm{n}=151$ & $\mathrm{n}=201$ \\
\hline \multirow{2}{*}{$\begin{array}{l}\text { Health problems make me } \\
\text { more dependent on others } \\
\text { than I want }\end{array}$} & 9.95 & 9.45 & 5.47 & 14.9 & 60.2 & 100 \\
\hline & $\mathrm{n}=20$ & $\mathrm{n}=19$ & $\mathrm{n}=11$ & $\mathrm{n}=30$ & $\mathrm{n}=121$ & $\mathrm{n}=201$ \\
\hline \multirow{2}{*}{$\begin{array}{l}\text { The disease makes me a } \\
\text { burden for my family and } \\
\text { friends }\end{array}$} & 1.49 & 1.99 & 1.99 & 8.46 & 86.1 & 100 \\
\hline & $\mathrm{n}=3$ & $\mathrm{n}=4$ & $\mathrm{n}=4$ & $\mathrm{n}=17$ & $\mathrm{n}=173$ & $\mathrm{n}=201$ \\
\hline \multirow{2}{*}{$\begin{array}{l}\text { My health makes me feel } \\
\text { like I'm not a complete } \\
\text { person }\end{array}$} & 3.98 & 7.46 & 4.98 & 10.5 & 73.1 & 100 \\
\hline & $\mathrm{n}=8$ & $\mathrm{n}=15$ & $\mathrm{n}=10$ & $\mathrm{n}=21$ & $\mathrm{n}=147$ & $\mathrm{n}=201$ \\
\hline \multirow{2}{*}{$\begin{array}{l}\text { I will never be self sufficient } \\
\text { as much as I would like }\end{array}$} & 15.9 & 8.46 & 44.8 & 17.9 & 53.2 & 100 \\
\hline & $\mathrm{n}=32$ & $\mathrm{n}=17$ & $\mathrm{n}=9$ & $\mathrm{n}=36$ & $\mathrm{n}=107$ & $\mathrm{n}=201$ \\
\hline \multirow{2}{*}{$\begin{array}{l}\text { I think the people around me } \\
\text { are often embarrassed about } \\
\text { my illness }\end{array}$} & 4.48 & 3.98 & 6.97 & 9.95 & 74.6 & 100 \\
\hline & $\mathrm{n}=9$ & $\mathrm{n}=8$ & $\mathrm{n}=14$ & $\mathrm{n}=20$ & $\mathrm{n}=150$ & $\mathrm{n}=201$ \\
\hline
\end{tabular}

\section{Results}

Degree of disease acceptance

\begin{tabular}{|c|c|c|c|c|}
\hline \multirow{3}{*}{ Results } & & & & \multirow{3}{*}{ Summary } \\
\hline & low & medium & high & \\
\hline & 8-19 & 20-35 & $36-40$ & \\
\hline Number of patients & $\mathrm{n}=13$ & $\mathrm{n}=77$ & $\mathrm{n}=111$ & $\mathrm{n}=201$ \\
\hline Percentage of patients (\%) & 6.47 & 38.30 & 55.20 & 100 \\
\hline
\end{tabular}


Table 3. Analysis of the impact of selected factors on the degree of disease acceptance (AIS) in the group of kidney transplantation patients.

\begin{tabular}{|c|c|c|c|c|}
\hline Group & $\begin{array}{l}\text { Median } \\
\text { score }\end{array}$ & $\begin{array}{l}\text { Interquartile } \\
\text { range* }\end{array}$ & $\begin{array}{l}\text { Number of } \\
\text { patients } \mathbf{N}\end{array}$ & $\begin{array}{c}\text { Test Mann- } \\
\text { Whitney U } \\
\qquad p\end{array}$ \\
\hline age $\leq 50$ & 37.0 & $33.0-40.0$ & 79 & \multirow{2}{*}{0.0711} \\
\hline age $>50$ & 35.0 & $30.0-39.0$ & 122 & \\
\hline vocationally active & 38.0 & $35.0-40.0$ & 69 & \multirow{2}{*}{$0.00010 * *$} \\
\hline vocationally not active & 35.0 & $29.0-39.0$ & 132 & \\
\hline number of taken medicines $\leq 5$ & 38.0 & $34.0-40.0$ & 67 & \multirow[b]{2}{*}{$0.00156^{* *}$} \\
\hline number of taken medicines $>5$ & 35.0 & $30.0-39.0$ & 134 & \\
\hline no additional diseases & 39.0 & $36.0-40.0$ & 34 & \multirow{2}{*}{$0.00443 * *$} \\
\hline additional diseases & 36.0 & $31.0-39.0$ & 167 & \\
\hline acceptance of treatment costs & 38.0 & $33.0-40.0$ & 101 & \multirow{2}{*}{$0.00035 * *$} \\
\hline non-acceptance of treatment costs & 34.0 & $28.5-39.0$ & 100 & \\
\hline no pharmacist's assistance & 38.0 & $33.0-40.0$ & 123 & \multirow{2}{*}{$0.00093 * *$} \\
\hline pharmacist's assistance & 34.0 & $25.0-39.0$ & 78 & \\
\hline no attention from medical staff & 37.0 & $33.0-40.0$ & 141 & \multirow{2}{*}{0.0146} \\
\hline more attention from medical staff & 33.5 & $28.0-39.5$ & 60 & \\
\hline
\end{tabular}

*Interquartile range $25 \mathrm{Q}-75 \mathrm{Q} * *$ Bonferroni-adjusted $\mathrm{p}$ value $=0.00714$

involved, the number of medications taken, comorbidities, and treatment costs. The greater interest from medical staff and the potential

Patients over 50 years of age obtained significant lower scores of the AIS test, they showed worse acceptance of their health condition as compared to younger people, which was consistent with the observations of other authors in patients undergoing dialysis, with systemic connective tissue diseases or women with osteoporosis $(11,18,19)$. Surprisingly, Kobylańska et al. found worse effectiveness of rehabilitation in patients under 55 after stroke.

It seems that younger, socially, and vocationally active people experience a deeper crisis (23). Chrobak-Bień et al. did not observe the relationship between age and disease acceptance in patients with ulcerative colitis (22).

Social factors worsening the health situation include a sudden change in living conditions (e.g. retirement, disability), loneliness, social isolation, poor financial situation, an inability to use free time (24). This was confirmed by our study which showed a significantly higher disease acceptance rate in working people compared to retired or disabled. Similar results were obtained in patients with type 2 diabetes or systemic connective tissue diseases $(12,19)$. Jordakieva et al. demonstrated that employed kidney transplant recipients more often stay in a relationship with a partner, have higher education and better quality of life (25). For many patients, work is the meaning of life, it allows participation of the pharmacist in posttransplantation care were other important issues for the surveyed patients.

them to maintain self-esteem, safety and prevents loneliness $(23,24)$.

The number of medications taken also has a significant impact on the attitude towards one's illness. Our study found that with their increasing number, the degree of disease acceptance decreases. Particular attention should be paid to elderly patients, as drug-related complications are 10 times more frequent in them than in younger patients. The number of medications taken may also affect the degree of adherence to medical recommendations. A meta-analysis by Simpson et al. indicated that after 6 months of therapy, less than half of the patients continue the recommended treatment (26). The correlations between the degree of disease acceptance and the number of taken medications were analysed in older patients in a rehabilitation centre before and after rehabilitation procedures. However, no significant relationships were found (27).

Treatment of a kidney transplantation patient is significantly cheaper for the health care system than a cure of a dialyzed person, except for the first year after transplantation. The most important component of the therapy costs is the life-long purchase of immunosuppressive drugs (28). The introduction of generic drugs allows for cost reduction, but not all original medicines have equivalents. Moreover, in transplant recipients it is 
not always possible to replace them. Additionally, costs related to the required monitoring of drug concentration, the treatment of complications, a biopsy of the transplanted organ with its histopathologic evaluation should also be taken into account. As our observations have shown, the degree of disease acceptance significantly depends on the overall cost of therapy. Patients declaring large treatment expenses obtained much lower scores in the AIS test as compared to the group who paid less. This indicates that the cost of therapy may play a significant role in the whole treatment process.

Our results showed no correlation between gender, level of education, marital status, time after the kidney transplantation and the level of disease acceptance. Similar observations were made by Staniszewska et al. in patients with epilepsy (21). Janiszewska et al. did not find a correlation between the marital status, support by health care and the acceptance of health condition of osteoporosis patients but demonstrated such correlation with the level of education and support of friends (18).

Comprehensive care for a kidney recipient involves optimization and individualization of immunosuppressive treatment, monitoring the transplant function, early detection, and treatment of complications, preventing their occurrence and educating the patients. For some patients, the effectiveness of the treatment requires understanding and acceptance of the disease and its limitations. It is important for them to deepen the perception of their own health, learn how to take care of their body's resistance and prevent infections, how to lead a proper lifestyle to maintain the transplanted organ (1).

Our observations showed a significant correlation between the degree of disease acceptance and the patients' reporting the need for more attention from medical staff and their willingness to cooperate with a pharmacist. Clinical pharmacists, who in many countries are actively involved in the process of care of transplantation and dialysis patients, may be helpful in meeting these needs. This is proven for example by the results of studies carried out by Martin and Zavala in 36 transplantation centers in the USA where pharmacists were included into the multidisciplinary clinical transplantation teams (29). They perform their activities from the moment the patient is prepared for transplantation, through perioperative care, to supervision after the transplantation procedure. In one Chinese study, a comprehensive assessment of the impact of posttransplantation pharmacotherapy management under the supervision of clinical pharmacists showed a reduction in the average cost of medication per patient, a significant reduction in the frequency and duration of antibiotic therapy, and an increase in the percentage of patients whose tacrolimus levels were within the target range. The presence of a clinical pharmacist in an interdisciplinary team also improves compliance with medical recommendations. The process of pharmaceutical care rationalization includes conducting drug reviews with regard to detecting undesirable interactions between taken medicinal products or between them and dietary supplements, and in a personalized therapy with immunosuppressive drugs, also monitoring their concentration and consulting obtained results along with conducting genetic tests important for their dosage (30).

Identification and optimization of modifiable risk factors of various disorders observed in renal transplantation patients may also be the domain of pharmacists' actions. Their involvement in the education process not only of the patient but also of the patient's family or caregivers in the area of lifestyle changes such as smoking cessation, appropriate exercising or maintaining proper body weight is invaluable $(2,3)$. The knowledge and practical skills of how to support patients during the post-transplantation period and late convalescence is of prime importance. In the perioperative period, many patients are disappointed with their malaise, poor response to the treatment and delayed transplanted kidney function. Medical staff, including pharmacists, should provide information and educational support for elderly patients whose difficulties in health education result from impaired vision, hearing or perception of new content. It has been shown that the risk of death is reduced by about $41 \%$ in chronically ill patients who take medication as a result of regular consultations with pharmacists. Klewitz et al. demonstrated that kidney transplantation patients are not satisfied with the information on adverse effects of immunosuppressants, especially with regard to sleep (57.1\%) and sexual life (56.3\%) (31). Nielsen et al. have suggested that it is reasonable to use modern telehealth technologies for kidney recipients (32).

\section{LIMITATIONS}

This study was subject to the inherent limitations of survey-based methods, including the patient's bias. It was not possible to verify the truthfulness of the participants' answers; therefore, the validity of our results may be limited. 
The population of participants, although covering all patients hospitalized in the selected period, was not a randomized selection and the number of participants was relatively small, so results should be interpreted with caution. More research is needed to confirm such observations.

\section{CONCLUSIONS}

The studied renal transplantation patients differed in their level of adaptation to the disease. More effort must be made to reduce the number of people showing average and poor levels. Identification of factors differentiating the degree of disease acceptance such as: age, occupational activity, number of coexisting diseases, the number of medications taken, and the cost of therapy suggests that they should be taken into account during post transplantation care. It can be concluded that with the decreasing acceptance of one's health, the patient's interest in cooperating with a pharmacist increase. The reported need for professional help indicates the necessity to establish a multidisciplinary therapeutic team, in which a clinical pharmacist should play a special role as an educator, verifier of compliance and correctness of drug use. The performance of such an activity by a clinical pharmacist should influence the degree of disease acceptance among posttransplantation patients.

CONFLICTS OF INTEREST. none declared.

FUNDING. The authors received no financial support for the research, authorship, and/or publication of this article.

\section{REFERENCES}

1. De Pasquale C, Pistorio ML, Veroux M, et al. Psychological and Psychopathological Aspects of Kidney Transplantation: A Systemic Review. Front. Psychiatry 2020;11:106.

doi:10.3389/fpsyt.2020.00106.

2. Carminatti $M$, Tedesco-Silva $H$, Silva Fernandes NM, Sanders-Pinheiro H. Chronic kidney disease progression in kidney transplant recipients: a focus on traditional risk factors. Nephrology (Carlton) 2019;24:141-147. doi:

10.1111/nep. 13483

3. Taber DJ, Pilch NA, Trofe-Clark J, Kaiser TE. A National Survey Assessing the Current Workforce of Transplant Pharmacists Across Accredited U.S. Solid Organ Transplant Programs. Am. J.
Transplant 2015;15:2683-2690. doi: 10.1111/ajt.13323

4. Cohen-Bucay A, Gordon CE, Francis JM. Non-immunological complications following kidney transplantation. F1000 Res. $2019 ; 8$. doi:10.12688/f1000research.16627.1.

5. Devine PA, Courtney AE, Maxwell AP. Cardiovascular risk in renal transplant recipients. J. Nephrol. 2019;32:389-399. doi: 10.1007/s40620-018-0549-4.

6. Chadban SJ, Ahn C, Axelrod DA, et al. Summary of the kidney disease: Improving Global Outcomes (KDGIO) Clinical Practice Guideline on the Evaluation and Management of Canditates for Kidney Transplantation. Transplantation 2020;104:708-714.

doi: 10.1097/TP.0000000000003137.

7. Król J, Szcześniak M, Koziarska D, Rzepa T. Time perception and illness acceptance among remitting-relapsing multiple sclerosis patients under treatment. Psychiatr. Pol. 2015;49:911-920. doi: $10.12740 / \mathrm{PP} / 38740$

8. Hornik B, Duława J. Frailty, Quality of Life, Anxiety, and Other Factors Affecting Adherence to Physical Activity Recommendations by Hemodialysis Patients. Int. J. Environ. Res. Public Health, 2019;16: 827. doi:10.3390/ijerph16101827.

9. Reese PP, Tehrani T, Lim MA et al. Determinants of the Decision to Accept a Kidney From a Donor at Increased Risk for Blood-Borne Viral Infection. Clin J Am Soc Nephrol 2010;5: 917-923.

doi: 10.2215/CJN.08251109.

10. Chan R. The effect of acceptance on health outcomes in patients with chronic kidney disease. Nephrol Dial Transplant 2013;28:11-14. doi: 10.1093/ndt/gfs334.

11. Schneider-Matyka D, Klim M, Szkup M, Starczewska M, Wieder-Huszla S, Grochans E. The level of illness acceptance among haemodialysis and peritoneal dialysis patients. J. Public Health Nurs. Med. Rescue, 2016;2:51-57.

12. Mazurek J, Lurbiecki J. Acceptance of Illness Scale and its clinical impact. Polski Merkuriusz Lekarski. 2014;36(212):106108.

13. Lelonek B, Kaczmarczyk M. Adjustment to illness in patients treated in the surgery ward. Stud. Med. 2011;24:45-52.

14. Zimmermann $\mathrm{T}$, Pabst S, Bertram A, Schiffer M, de Zwann M. Differences in emotional responses in living and deceased 
donor kidney transplant patients. Clin. Kidney J. 2016;9: 503-509. doi: $10.1093 / \mathrm{ckj} / \mathrm{sfw} 012$.

15. Tucker EL, Smith AR, Daskin MS, et al. Life and expectations post-kidney transplant: a qualitative analysis of patient responses. BMC Nephrology, 2019;20. doi:10.1186/s12882-019-1368-0.

16. Paterson TSE, Demian M, Shapiro RJ, Thornton WL. Impact of Once-Versus Twice-Daily Tacrolimus Dosing on Medication Adherence in Stable Renal Transplant Recipients: A Canadian SingleCenter Randomized Controlled Trial. Can. J. Kidney Health Dis. 2019. doi:10.1177/2054358119867993.

17. Sobczak-Kaleta MA, Qawoq HD, Krawczyk $\mathrm{M}$, et al. Cognitive behavioral intervention improves quality of life and perceived illness acceptance in patients after cardiac electrotherapy devices implantation. Psychiatr. Pol. 2019;53:1037-1051.

doi: 10.12740/PP/109217.

18. Janiszewska M, Barańska A, Jędrych T, Kulik T, Kasperek J, Drop B. The impact of selected factors on acceptance of illness and life satisfaction among female residents of rural areas treated for osteoporosis. Ann. Agric. Environ. Med. 2019;26:592-599. doi: 10.26444/aaem/109598.

19. Puto G, Repka I, Zurzycka P, Kowalska U. Socio-demographic determinants of the acceptance of systemic connective tissue diseases. Reumatologia 2018;56:31-36. doi: 10.5114/reum.2018.74746.

20. Dymecka J, Bidzan M. Biomedical Variables and Adaptation to Disease and Health-Related Quality of Life in Polish Patients with MS. Int. J. Enviton. Res. Public Health, 2018;15. doi: 10.3390/ijerph15122678.

21. Staniszewska A, Religioni U, DąbrowskaBender M. Acceptance of disease and lifestyle modification after diagnosis among young adults with epilepsy. Patient Prefer. Adherence 2017;11:165-174. doi: 10.2147/PPA.

22. Chrobak-Bień J, Gawor A, Paplaczyk M, et al. The influence of socio-demographic and clinical factors on the process of acceptance of the disease among patients with ulerative colitis. Polski Przegląd Chirurgiczny 2018;90:6-12. doi: 10.5604/01.3001.0012.1753.

23. Kobylańska M., Kowalska J., Neustein J., Mazurek J., Wójcik B., Bełza M., Cichosz M., Szczepańska-Gieracha J.: The role of biopsychosocial factors in the rehabilitation process of individuals with a stroke. Work 2018;61:523-535. doi: 10.3233/WOR162823.

24. Kulik TB, Janiszewska M, Piróg E, et al. Health situation of the elderly in Poland and other European countries, Medycyna Ogólna i Nauki o Zdrowiu 2011;17:90-95.

25. Jordakieva G, Grabovac I, Steiner M, et al. Employment Status and Associations with Workability, Quality of Life and Mental Health after Kidney Transplantation in Austria. Int. J. Environ. Res. Public Health 2020;17:1254. doi:10.3390/ijerph17041254.

26. Simpson S, Eurich DT, Majumdar SR, et al. A meta-analysis of the association between adherence to drug therapy and mortality. BMJ 2006;333:15. doi:10.1136/bmj.38875.675486.55.

27. Kowalska J, Wolny K, Kobylańska M, Wójcik B. The degree of acceptance of illness and functional status among elderly people staying in the rehabilitation centre. Geriatria 2015;9:3-9. doi: 10.2147/CIA.S268095.

28. Łabuś A, Niemczyk M, Czyżewski Ł, et al. Costs of Long-term Post-Transplantation care in Kidney Transplant Recipients. Ann. Transplant 2019;24:252-259. doi: 10.12659/AOT.914661.

29. Martin JE, Zavala EY. The Expanding Role of the Transplant Pharmacist in the Multidisciplinary Practice of Transplantation. Clin. Transplant 2004;18:(12),50-54. doi: 10.1111/j.13990012.2004.00218.x.

30. Yang $\mathrm{H}, \mathrm{Li} \mathrm{L}, \mathrm{Hu} \mathrm{X}$, et al. Impact of pharmacist - led post-transplant medication management for kidney transplant recipients: A retrospective pre- and post-intervention study. J. Clin. Pharm. Ther 2020. doi.org/10.1111/jcpt.12826.

31. Klewitz F, Nöhre M, Bauer-Hohmann M, et al. Information Needs of Patient About Immunosuppressive medication in a German Kidney Transplant Sample: Prevalence and Correlates. Front. Psychiatr 2019;10:1-13. doi: 10.3389/fpsyt.2019.00444.

32. Nielsen C, Agerskov H, Bistrup C, Clemensen J. Evaluation of a telehealth solution developed to improve follow-up after kidney Transplantation. J. Clin. Nurs 2020;29:1053-1063.

doi: $10.1111 /$ jocn. 15178 